\title{
The Circulation of the Human Limbus
}

\author{
PAUL A. R. MEYER \\ Cambridge
}

\begin{abstract}
Summary
The superficial circulations of the anterior segment of the human eye have been studied by the following techniques: photographic and video low-dose fluorescein angiography, video-microscopy using red-free light and stereoscopic colour photography. The results are combined to give a dynamic description of the limbal circulation, including its arterial supply and venous drainage.
\end{abstract}

\section{Limbal vessels}

In order to achieve optical clarity, blood vessels are excluded from the cornea in most species of mammal: this is possible because its metabolic activity is matched by the delivery of glucose and oxygen from aqueous and tears. ${ }^{1}$ However, the requirements of the corneo-scleral junction are substantially greater. Corneal epithelium is largely renewed from limbal stem cells, ${ }^{2,3}$ and there is evidence that the drainage of aqueous may be metabolically demanding. ${ }^{4}$

These demands are met by an elaborate limbal capillary bed. The corneal epithelium is supplied by a monolayer of superficial arcades, and beneath these a receding bank of capillaries reaches down to the Canal of Schlemm.

Capillaries of the limbus have thicker endothelium and fewer fenestrations than those of the conjunctiva. ${ }^{5}$ They are anchored within the corneal collagen matrix by a highly organised adhesive of proteoglycan. ${ }^{6,7}$

\section{Capillary growth and regression}

This unusual circulation, much of which is imprisoned in collagen, might be considered unsuitable for studies of mediators affecting vessel growth. However, the transparency of the cornea has attracted many researchers and we know more about the control of capillary growth here than at any other site in the body.

Vascular invasion of cartilage is inhibited by a factor extractable from bovine aorta, ${ }^{8}$ thought to be chondroitin sulphate. ${ }^{9}$ This forms about 30 per cent of corneal proteoglycan, ${ }^{1}$ and the penetration of clear cornea by limbal capillaries may be suppressed in the same way, although other hypotheses have been proposed. ${ }^{10}$

When placed within stromal pockets, tumour angiogenic factor, ${ }^{11,12}$ fibroblast growth factor, ${ }^{13}$ epidermal growth factor, ${ }^{13}$ catecholamines ${ }^{14}$ and prostaglandins (particularly PGE1) ${ }^{15,16}$ all stimulate limbal neovascularisation. Hypoxia also appears to cause limbal vessels to proliferate, possibly as a result of the accumulation of ADP or lactic acid. ${ }^{17}$ This may account for the corneal vascularisation that accompanies epithelial keratinisation in vitamin A deficiency. ${ }^{18}$

Activated lymphocytes release angiogenic mediators, ${ }^{19}$ which may explain the neovascular response to infection, corneal foreign bodies and grafts. This process is facilitated by granulocytes, ${ }^{19,20}$ but not dependent upon them. ${ }^{21,22}$

Therefore there is no single map of the limbal arcades. They form a cylindrical bank of 
capillaries which may wax and wane according to environmental influences.

\section{Vascular relationships}

According to Leber's classical account, ${ }^{23}$ the anterior segment of the human eye has deep and superficial circulations which both arise from the ophthalmic artery:

The long posterior ciliary arteries penetrate the globe behind the equator, run forward within sclera, and cross the supra-choroidal space to join the major circle of the iris. This intra-ocular arterial circle (which has recently been shown to have an additional intra-muscular component ${ }^{24}$ ) supplies the iris and ciliary apparatus.

The anterior ciliary arteries-superficial, anterior continuations of the arteries to the rectus muscles-were thought to supply the limbus, anterior conjunctiva and episclera.

In 1903 Leber was clear that the superficial and deep circulations were joined anteriorly by substantial arteries that perforated the sclera and crossed the supra-choroidal space. His findings have since been confirmed by vascular castings, ${ }^{24.25}$ but the direction of flow in these vessels has excited controversy.

Whether studied by fluorescein angiography, ${ }^{26}$ or by the injection of radio-labelled microspheres, ${ }^{27}$ iris perfusion is found to decline after section of the rectus muscles. This has been considered to indicate that the muscular/anterior ciliary arteries contribute to the deep circulation. ${ }^{26.27}$

Photographic fluorescein angiography of the anterior ciliary arteries themselves has yielded conflicting evidence. A number of investigators have published angiographic sequences in which anterior ciliary arteries appeared to fill away from the limbus. ${ }^{28,29,30}$ Others have argued ${ }^{31.32}$ that these represent emissary veins, known to drain the deep circulations of the ciliary apparatus into the superficial episcleral venous system. ${ }^{33}$

Squint surgery upon the vertical, but not the horizontal, rectus muscles may give rise to perfusion defects in iris fluorescein angiograms. ${ }^{34}$ This has prompted the suggestion that the circle of arteries in the iris root and ciliary muscle (intra-ocular arterial circle) may receive blood from the muscular arteries in the vertical meridian and the long posterior ciliary arteries in the horizontal meridian. ${ }^{34}$

However, a recent study, in which emissary veins and anterior ciliary arteries were distinguished by anterior segment fluorescein videoangiography, has shown that, both in the horizontal and vertical meridians, most arteries and all veins do carry blood away from the limbus. ${ }^{35}$ The circulations of the anterior ocular surface are therefore predominantly supplied from within the globe.

The classical, static anatomical techniques of indian ink injections ${ }^{33}$ and vascular casting ${ }^{36,37}$ do form the foundation for our knowledge of the limbal vasculature. . $38,39^{3}$ However, when circulatory dynamics are to be described, there is no substitute for imaging a living circulation using techniques such as fluorescein angiography ${ }^{35,40}$ and video recording in red-free light. ${ }^{41}$

\section{Low dose anterior segment fluorescein angiography}

Retinal fluorescein angiography has been practised since $1960,{ }^{42}$ but extravasation of fluorescein has limited the value of anterior segment studies. However, by restricting the dose of fluorescein to prevent the saturation of available ionic binding to circulating albumin, ${ }^{43.44}$ leakage from conjunctival capillaries may be reduced and resolution enhanced. ${ }^{40}$ Low dose fluorescein angiograms may be recorded photographically to give high spatial resolution, or by video to achieve higher temporal resolution.

\section{Video recording in red-free light}

The clinical use of red-free light to observe blood flow in the anterior segment of the eye is commonplace. However, this is difficult to record by video since restriction of the bandwidth of illumination lowers light intensity, and most video cameras have enhanced sensitivity to longer wavelengths. The technique used for this study represents a compromise, in which a broad waveband of illumination below $600 \mathrm{~nm}$ is recorded by a CCD camera which achieves peak sensitivity at $520 \mathrm{~nm}$.

This account of the limbal circulation concatenates the results of recent studies using both techniques, paying particular regard to 
flow dynamics, arterial supply and venous drainage.

\section{Methods \\ Photographic low dose fluorescein angiography}

The descriptions below are based upon findings in eight normal subjects, which have been reported previously. ${ }^{40}$ Each volunteer received one angiogram and colour photographs of the angiographic field.

Sodium fluorescein $(120 \mathrm{mg})$ was injected briskly into an ante-cubital fossa vein. The eye was illuminated at 1.5 second intervals by 720 Wsec flashes from an off-axis xenon flash unit, mounted on a Zeiss photo-slit lamp. The exciting radiation was filtered by a 420 $490 \mathrm{~nm}$ interference band pass filter; a long pass filter $(\mathrm{T} 50=515 \mathrm{~nm})$ was placed in the imaging pathway. Photographs were taken using the $\times 16$ setting on the objective turret and a $\times 2$ magnifier (a magnification factor of 3.5 at the camera back). 400 ASA monochrome film (Kodak Tri-X) was used, but was developed to 1200 ASA using Acuspeed developer (Patterson).

\section{Low dose fluorescein videoangiography}

These results are taken from studies of 15 normal volunteers. ${ }^{35}$ The subjects received angiograms at low (13 mm/vertical screen) and high $(8 \mathrm{~mm} /$ vertical screen $)$ magnification, in addition to 360 degree stereo colour photographic surveys.

Sodium fluorescein $(1.5 \mathrm{mg} / \mathrm{kg})$ was injected as a brisk bolus. The eye was illuminated by a 25 watt incandescent bulb. A 450 $490 \mathrm{~nm}$ band pass filter was used for excitation and a long pass filter $(\mathrm{T} 50=515 \mathrm{~nm})$ for imaging. The angiograms were recorded on lowband U-matic videotape, using an imageintensified nuvicon (Visual Contacts) mounted on the video arm of a Zeiss clinical slit lamp. The images were then transferred onto one inch videotape and slowed to onefifth real time for analysis.

\section{Red-free video-microscopy of limbal capillaries}

The limbal circulation of one eye was observed at low ( $8 \mathrm{~mm} /$ vertical field) and high $(1.5 \mathrm{~mm} /$ vertical field) magnification in four normal subjects. Three hundred and sixty degree surveys were performed, with special reference to the changes in flow characteristics that accompany transit of blood through the limbal capillary bed and the anatomy of venous drainage.

Illumination was by a 25 -watt incandescent lamp, filtered by a $500-580 \mathrm{~nm}$ band-pass interference filter.

Recordings were made on low-band U-matic videotape using a COHU 4712 CCD camera.

\section{Results and Discussion \\ Delivery of Blood to the Anterior Segment (low-dose fluorescein videoangiography)}

Using low-dose fluorescein videoangiography, arteries and veins may be distinguished by their flow characteristics and direction of flow can be recorded even when velocity is high. The velocity of an advancing fluorescein front may be estimated, but this is not reliable.

A study of 40 radial arteries from 15 subjects demonstrated that more than $60 \%$ of anterior ciliary arteries filled from scleral perforations close to the limbus and flowed back towards the rectus muscles. They gave rise to circumferential branches (the episcleral arterial circle) and radial vascular trunks, some of which met muscular arteries flowing in the opposite direction. This pattern of perfusion was found in both the horizontal and vertical meridians.

If arteries communicate directly (end to side or end to end), they may be presumed to support the free shunting of blood. Such arterial communications can be detected by videoangiography when each vessel gives rise to a separate run-off: the intervening column of blood remains static, non-fluoresceinated and gently pulsating.

This sign was observed close to the insertions of the horizontal and vertical rectus muscles, and within perforating anterior ciliary arteries. This indicates that the saggittal arterial ring, composed of long posterior ciliary arteries (lpca) and perforating scleral arteries, muscular arteries and anterior ciliary arteries (aca), may indeed support the shunting of arterial blood. Direct arterial communication is also demonstrable in the episcleral 
arterial circle (eac), indicating that this, too, is a true arterial shunt circulation.

Therefore the arterial circulation of the anterior segment is composed of superficial and deep coronal arterial circles (the eac and the major circle of the iris + intramuscular circle, respectively). These are fed and joined by a saggittal arterial ring (lpca + perforating scleral arteries + aca/muscular arteries) (Fig. 1). Blood is most commonly delivered to both coronal circles from within the globe, presumably by the long posterior ciliary arteries.

Limbal Vascular Anatomy (Figs. 1 and 2) (episcleral arterial circle [photographicl video-fluorescein angiography] red-free video-microscopy)

The circumferential branches of anterior cili-

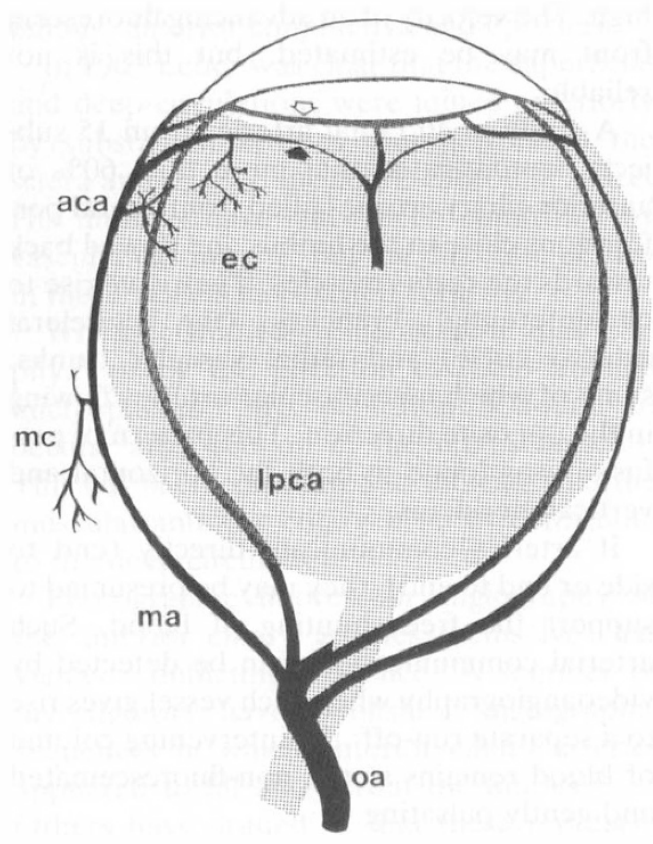

Fig. 1. Delivery of blood to the anterior segment. oa ophthalmic artery.

lpca long posterior ciliary artery. ) (saggittal

ma artery of rectus muscle. $\}$ arterial

aca anterior ciliary artery. $\quad$ ring)

- episcleral arterial circle (superficial coronal arterial circle).

$\square \quad$ major circle of iris +intra-muscular arterial circle (deep coronal arterial circle).

ec episcleral capillaries.

mc capillaries of rectus muscle. ary arteries meet each other in the episcleral arterial circle, which lies 1 to $5 \mathrm{~mm}$ behind the limbus. In man this may have superficial and deep components, giving the appearance of discontinuity.

Photographic fluorescein angiography has shown that the eac distributes blood to the anterior surface of the globe. Posterior roots supply the episcleral capillary net, but anterior roots run forwards to the reflection of the conjunctiva. There they divide into fine conjunctival arterioles that loop back radially, and more delicate vessels that feed the limbal capillaries.

\section{Limbal Capillaries}

(photographic fluorescein angiography; redfree video-microscopy)

Each limbal arteriole supplies between one and three superficial limbal capillaries. These repeatedly divide and coalesce, forming a network of interconnected vessels one to four tiers deep. Whereas conjunctival vessels leak fluorescein from discrete fenestrations, the limbal arcades remain competent until late in an angiogram, when they become uniformly obscured by fluorescein, possibly as a result of diffusion from the subconjunctival space.

\section{Limbal Veins}

(stereoscopic colour photography; red-free video-microscopy)

Immediately behind the limbal arcades, and central to the episcleral arterial circle, lies a circle of fine veins which may be called the limbal venous circle. It can be composed of up to three communicating, parallel vessels. They collect blood from the anterior conjunctival veins and limbal arcades, and drain into radial episcleral collecting veins which flow towards the rectus muscles.

As they course across the anterior sclera, radial collecting veins are joined by anterior episcleral veins and veins that gradually emerge from the sclera (presumably draining the deeper limbal capillaries). They also meet the larger emissary veins that emerge from scleral foramina. They leave the anterior surface of the globe over the rectus muscles.

Veins draining aqueous surface into both the limbal venous circle and the radial collecting veins. 


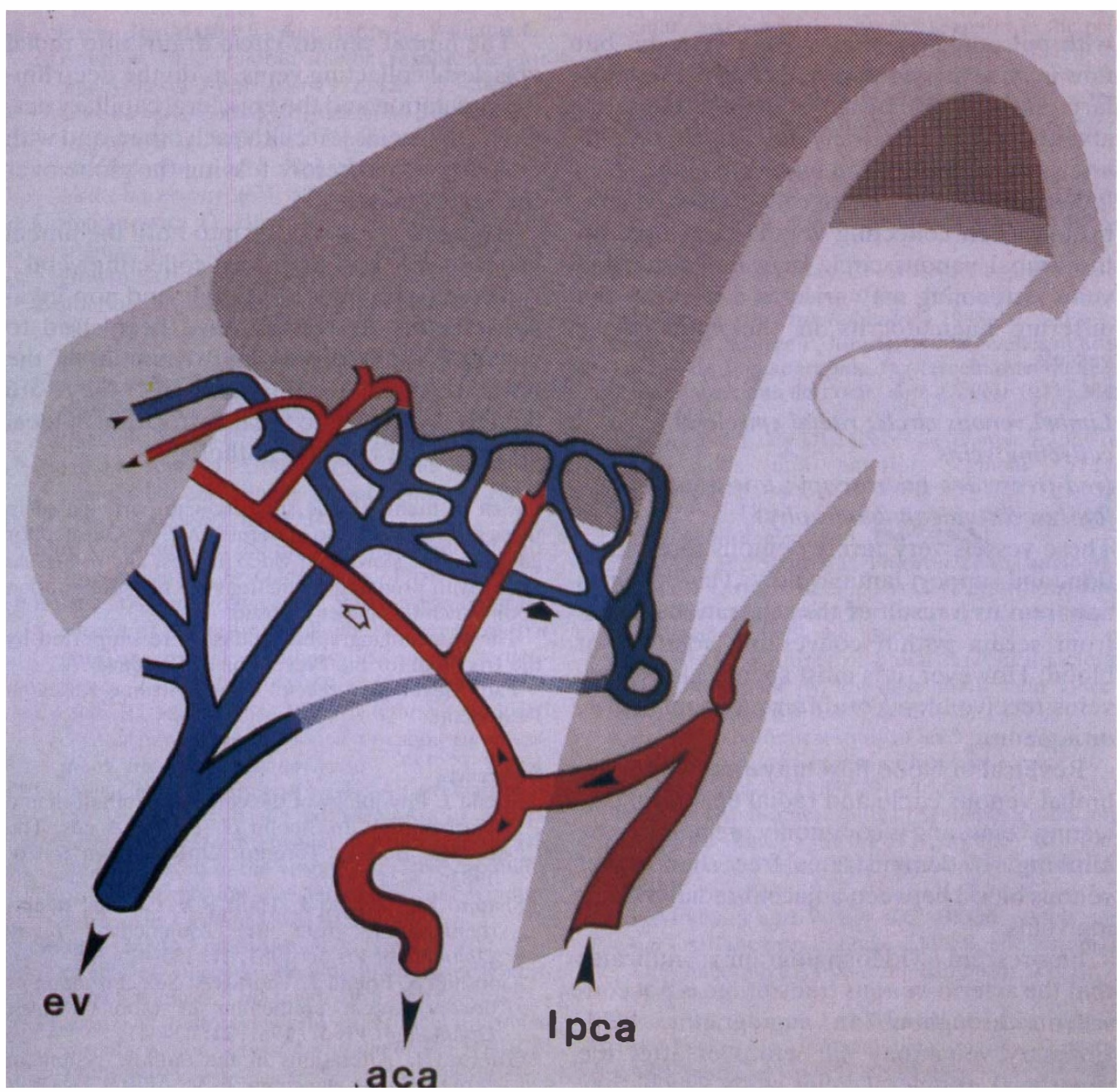

Fig. 2. The limbal circulation.

lpca long posterior ciliary artery.

aca anterior ciliary artery.

$\triangle \quad$ episcleral arterial circle.

- limbal venous circle.

ev radial episcleral collecting vein.

\section{Blood Flow Dynamics}

\section{Anterior ciliary arteries}

(low-dose fluorescein videoangiography)

Anterior ciliary arteries usually fill early in a videoangiogram. They carry blood with pulsatile flow and velocities of up to $100 \mathrm{~mm} /$ sec. However, close to sites of direct arterial communication arteries may fluoresce very late, often after the adjacent veins. In these circumstances pulsation occurs, but blood flow is minimal (vs).

\section{Limbal arcades}

(red-free video-microscopy)

Perfusion may follow one of two patterns:

(1) Blood is delivered into the apices of the arcades and then meanders towards the most proximal limbal vessels, which are broadened to form the limbal venous circle.

(2) More rarely, arterial blood is delivered to both proximal and distal capillaries. The venous circle then bisects the limbal arcades.

Blood is injected into the limbal arcades 
with pulsatile flow and at high velocity, but flow is slowed and smoothed early in the capillary phase. The passage of cells through the arcades may be extremely slow, and the capillaries are often perfused by serum alone. This indicates that they filter cells, which is confirmed when collecting venules converge on the limbal venous circle or radial collecting veins: streaming may arise as a result of the differing haematocrits in the contributary vessels.

\section{Limbal venous circle; radial episcleral collecting veins \\ (red-free video-microscopy; low-dose fluorescein videoangiography)}

These vessels very rarely demonstrate pulsation, and support laminar flow. This becomes apparent as a result of the separation of cells from serum within converging columns of blood. However, it is most spectacular where veins receive blood of differing haematocrit, or aqueous.

Reversal of blood flow may arise within the limbal venous circle and radial episcleral collecting veins, and is commonly precipitated by blinking. It demonstrates free shunting of venous blood between adjacent radial collecting veins.

Fluorescein videoangiography indicates that the arterio-venous transit time is not consistent throughout an angiographic field. Emissary veins may fill before or after the superficial episcleral veins with which they join.

\section{Conclusion: The Limbal Circulation}

The ophthalmic artery gives rise to a saggittal arterial ring. Its deep component (the medial and lateral long posterior ciliary arteries) supplies a deep coronal arterial circle (major circle of iris + intramuscular circle) and usually delivers blood through perforating scleral arteries into a superficial coronal arterial circle (episcleral arterial circle).

From the episcleral arterial circle, blood is injected into the apices of the limbal arcades (and the conjunctival arterioles) at high velocity and with pulsatile flow. Flow is smoothed and slowed as it meanders towards the limbal venous circle, (which also receives the anterior conjunctival veins).
The limbal venous circle drains into radial episcleral collecting veins, as do the deep limbal circulation and the episcleral capillary net. Collecting veins join with each other, and with emissary veins, before leaving the globe over the rectus muscles.

Aqueous veins surface into both the limbal venous circle and the radial collecting veins.

These techniques are simple and non-invasive. In this study they have been used to elucidate the anatomy and dynamics of the normal limbal circulation, but they are equally applicable to the investigation of local and systemic vascular pathology.

I wish to thank all the subjects who participated in these studies. I am also grateful to Mr. A. Quested for advice on the slowing of video images, and to $\mathrm{Mr}$. A. Lacey who prepared animations for the presentation upon which this paper is based.

The videoangiographic studies were supported by the Iris Fund for the Prevention of Blindness.

Paul Meyer is in receipt of a Wellcome Research Fellowship.

\section{References}

${ }^{1}$ Friend J: Physiology of the cornea: metabolism and biochemistry. In Smolin G, Thoft RA eds. The cornea: Boston, Toronto: Little, Brown \& Co. 1983: 17-31.

2 Shapiro MS, Friend J, Thoft RA: Corneal re-epithelialisation from the conjunctiva. Invest Ophthalmol Vis Sci 1981, 21: 135-42.

${ }^{3}$ Kinoshita S, Friend J, Thoft RA: Sex chromatin of donor corneal epithelium in rabbits. Invest Ophthalmol Vis Sci 1981, 21: 434-41.

${ }^{4}$ Grierson I: Alterations in the outflow system in chronic simple glaucoma. In McAllister JA, Wilson RP eds. Glaucoma: London: Butterworths 1986: 1-29.

5 Iwamoto T and Smelser GK: Electron microscopic studies of corneal capillaries. Invest Ophthalmol Vis Sci 1965, 4: 815-34.

${ }^{6}$ Ausprunk DH, Boudreau CL, Nelson DA: Proteoglycans in the microvasculature I: histochemical localisation in microvessels of the rabbit eye. Am J Pathol 1981, 103: 353-66.

${ }^{7}$ Ausprunk DH, Boudreau CL, Nelson DA: Proteoglycans in the microvasculature II: histochemical localisation in proliferating capillaries of the rabbit cornea. Am J Pathol 1981, 103: 367-75.

${ }^{8}$ Eisenstein R, Goren SB, Shumacher B, Choromokos E: The inhibition of corneal vascularization with aortic extracts in rabbits. $A m \mathrm{~J}$ Ophthalmol 1979, 88: 1005-12.

${ }^{9}$ Eisenstein R, Meineke C, Shumacher B, Kuettner KE: Regulators in aorta (abstract) Am J Pathol 1977, 86: 32a-3a.

${ }^{10}$ Ashton N and Cook C: Mechanisms of corneal vascularisation. Br J Ophthalmol 1953, 37: 193-209. 
${ }^{11}$ Folkman JE, Marler E, Abernathy C, Williams G: Isolation of a tumour factor responsible for angiogenesis. J Exp Med 1971, 133: 275-88.

12 Gimbrone MA, Cotran RS, Leapman SB, Folkman $\mathrm{J}$ : Tumour growth and neovascularisation: an experimental model using the rabbit cornea. $J$ Natl Cancer Inst 1974, 52: 413-27.

${ }^{13}$ Gospodarowicz D, Bialecki H, Thakral TK: The angiogenic activity of fibroblast and epidermal growth factor. Exp Eye Res 1979, 28: 501-14.

${ }^{14}$ Zauberman H, Michaelson IC, Bergman F: Stimulation of neovascularisation of the cornea by biogenic amines. Exp Eye Res 1969, 8: 77-83.

${ }^{15}$ Ben Ezra D: Neovasculogenic ability of prostaglandins, growth factors and synthetic chemoattractants. Am J Ophthalmol 1978, 86: 455-61.

${ }^{16}$ Ziche M, Jones J, Gullino PM: Role of prostaglandin E1 and copper in angiogenesis. J Natl Cancer Inst 1982, 69: 475-82.

${ }^{17}$ Imre G: Studies on the mechanisms of retinal neovascularisation. Br J Ophthalmol 1964, 48: 75-82.

${ }^{18}$ Bessey DA and Wolbach SB: Vascularisation of the cornea of the rat in riboflavin deficiency, with a note on corneal vascularisation in vit. A deficiency. J Exp Med 1969, 69: 1-12.

${ }^{19}$ Epstein RJ and Hughes WF: Lymphocyte-induced corneal neovascularisation: a morphologic assessment. Invest Ophthalmol Vis Sci 1981, 21: 87-94.

${ }^{20}$ Fromer $\mathrm{CH}$ and Klintworth GK: An evaluation of the leukocytes in the pathogenesis of experimentally induced corneal vascularisation III: studies related to the vasoproliferative capability of polymorphonuclear leukocytes and lymphocytes. Am J Pathol 1976, 82: 157-67.

${ }^{21}$ Sholley MM, Gimbrone MA, Cotran RS: The effects of leucocyte depletion on corneal neovascularisation. Lab Invest 1978, 38: 32-40.

${ }^{22}$ Eliason JA: Leucocytes and experimental corneal vascularisation. Invest Ophthalmol Vis Sci 1978, 17: 1087-95.

${ }^{23}$ Leber T: Die Cirkulations- und Ernahrungsverhaltnisse des Auges. (Graefe-Saemisch Handbuch der Gesamten Augenheilkunde.) Leipzig: Engelmann, 1903, 2: ch.1.

${ }^{24}$ Morrison JC and Van Buskirk EM: Anterior collateral circulation in the primate eye. Ophthalmology 1983, 90: 707-15.

${ }^{25}$ Ashton $\mathrm{N}$ and Smith $\mathrm{R}$ : Anatomical study of Schlemm's canal and aqueous veins by means of Neoprene casts. Part III: arterial relations of Schlemm's canal Br J Ophthalmol 1953, 37: 57786.

${ }^{26}$ Virdi PS and Hayreh SS: Anterior segment ischemia after recession of various recti: an experimental study. Ophthalmology 1987, 94: 1258-71.

${ }^{27}$ Wilcox LM, Keough EM, Connolly RJ, Hotte CE: The contribution of blood flow by the anterior ciliary arteries to the anterior segment in the primate eye. Exp Eye Res 1980, 30: 167-74.

${ }^{28}$ Ikegami M: Fluorescein angiography of the anterior ocular segment. Part I: Hemodynamics in the anterior ciliary vessels. Acta Soc Ophthalmol Jpn 1974, 78: 39-53.

${ }^{29}$ Talusan ED and Schwartz B: Fluorescein angiography: demonstration of flow pattern in anterior ciliary arteries. Arch Ophthalmol 1981, 99: 107480 .

${ }^{30}$ Watson PG and Bovey E: Anterior segment fluorescein angiography in the diagnosis of scleral inflammation. Ophthalmology 1985, 92: 1-11.

${ }^{31}$ Amalric P, Rebiere P, Jourdes JC: Nouvelles indications de l'angiographie fluoresceinique du segment anterieur de l'oeil. Ann Oculist 1971, 204: 455-68.

${ }^{32}$ Bron AJ and Easty DL: Fluorescein angiography of the globe and anterior segment. Trans Ophthalmol Soc UK 1970, 90: 339-67.

${ }^{33}$ Kiss F: Der Blutkreislauf der Auges. Ophthalmologica 1943, 106: 225-50.

${ }^{34}$ Hayreh SS and Scott WE: Fluorescien iris angiography. II Disturbances in iris circulation following strabismus operation on the various recti. Arch Ophthalmol 1978, 96: 1390-400.

${ }^{35}$ Meyer PAR: Patterns of blood flow in episcleral vessels studied by low-dose fluorescein videoangiography. Eye 1988, 2: 533-46.

${ }^{36}$ Ashton N: Anatomical study of Schlemm's canal and aqueous veins by means of Neoprene casts. $\mathrm{Br} J$ Ophthalmol 1951, 35: 291-303.

${ }^{37}$ Ashton N: Anatomical study of Schlemm's canal and aqueous veins by means of Neoprene casts. Part II: aqueous veins. $\mathrm{Br} J$ Ophthalmol 1952, 36: 265-7.

${ }^{38}$ Duke-Elder S and Wybar KC: Blood vessels and nerves of the eye. In Duke-Elder S, ed. System of Ophthalmology: London: Kimpton, 1961; 2: chapter 4.

${ }^{39}$ Hogan MJ, Alvarad JA, Weddell JE: Histology of the human eye. Philadelphia, London, Toronto: WB Saunders Co, 1971: 119-26.

${ }^{40}$ Meyer PAR and Watson PG: Low dose fluorescein angiography of the conjunctiva and episclera. $\mathrm{BrJ}$ Ophthalmol 1987, 71: 2-10.

${ }^{41}$ Korber N, Jung F, Kiesewetter H, Wolf S, Prunte C, Reim M: Microcircualtion in the conjunctival capillaries of healthy and hypertensive patients. Klin Wochenschr 1986, 64: 953-5.

${ }^{42}$ Novotny HR and Alvis DL: A method for photographing fluorescence in circulating blood in the human retina. Circulation 1961, 24: 82-6.

${ }^{43}$ Brubaker FR, Penniston JT, Grotte DA, Nagataki $\mathrm{S}$ : Measurement of fluorescein binding in human plasma using fluorescence polarisation. Arch Ophthalmol 1982, 100: 625-30.

${ }^{44}$ Palestine AG and Brubaker RF: Plasma binding of fluorescein in normal subjects and in diabetic patients. Arch Ophthalmol 1982, 100: 1160-1. 